\title{
How Important Are Possessed Reasons?
}

\author{
Jonathan Way \\ University of Southampton
}

The final and definitive version of this paper will appear in Analysis. Please cite the published version.

Central to Errol Lord's excellent book is the notion of a possessed (objective, normative) reason. For Lord, rationality is a matter of correctly responding to possessed reasons, what rationality requires and permits is that we react in ways that are appropriate given our possessed reasons, and we ought - full stop - to react in ways that are decisively supported by our possessed reasons. Thus for Lord, possessed (objective, normative) reasons are very important indeed.

Part of the appeal and interest of this picture is its systematicity - Lord offers a unified and powerful story about rationality as part of a broader 'reasons fundamentalist' picture. Nonetheless, the devil resides, to a significant extent, in the details, and so it's worth examining the elements of Lord's picture on their own terms. In this paper, I'll look at three such elements. In $\S 1$, I offer objections to his accounts of rational requirements. In $\S 2$, I offer objections to a central argument for his view of what we ought to do. If successful, these objections suggest that possessed reasons are not as important as Lord thinks. In $§ 3$, I consider his account of possessed reasons itself.

\section{Coherence}


Lord proposes the following accounts of what rationality permits and requires (11):

\author{
Rational Permission What it is for a reaction ${ }^{1} \mathrm{R}$ of agent $\mathrm{A}$ to be rationally \\ permitted is for the reasons A possesses for $\mathrm{R}$ to be \\ sufficient.
}

Rational Requirement What it is for a reaction $\mathrm{R}$ of agent $\mathrm{A}$ to be rationally required is for the reasons A possesses for $\mathrm{R}$ to be decisive.

A central challenge to these accounts is to accommodate the apparent platitude that it is irrational to be incoherent - for example, to have inconsistent beliefs or intentions. ${ }^{2}$ Different forms of incoherence raise this challenge in different ways. I will focus on one of the most problematic cases. At least often, it is irrational to have inconsistent intentions - to intend to $\mathrm{A}$, intend to $\mathrm{B}$, and believe that you cannot both A and B. ${ }^{3}$ But it seems possible, indeed common, for your possessed reasons to sufficiently support these reactions. To take a standard example (cf. 36), you might possess sufficient reasons to intend to go to law school next year and sufficient reasons to intend to go to graduate school in philosophy next year (and decisive reasons to believe you can't do both - I'll take this as read). Nonetheless, it would be

\footnotetext{
1 'Reaction' is Lord's cover term for the types of things which can be subject to reasons - e.g. actions, beliefs, intentions.

${ }^{2}$ I do not think it is the only challenge - see Way $(2018: \S 4.2, \S 4.3)$ for two others. See Kiesewetter (2017: §9.4) for relevant discussion.

${ }^{3}$ These are 'broadly' inconsistent intentions. You have 'narrowly' inconsistent intentions if you intend to A and intend not to A. The discussion to follow would apply in much the same way in either case. Cf. $29 \mathrm{ff}$.
} 
irrational to both intend to go to law school and intend to go to graduate school.

Lord's account of what rationality permits and requires doesn't seem to generate this result.

Lord's solution to this problem is to propose:

Intentions Attenuate

When you have decisive reasons to believe that you

can't both $\varphi$ and $\psi$, intending to $\varphi$ attenuates the weight

of your reasons to intention to $\psi$. In cases where you

would otherwise possess sufficient reasons to intend to

$\varphi$ and to intend to $\psi$, this attenuation makes your

reasons to intend to $\psi$ insufficient (cf. 31).

So before forming an intention between law school and graduate school, you might

have had sufficient reasons for each intention. But once you form an intention, things change. Once you intend, say, to go to law school, this attenuates your reasons to intend to go to graduate school. They will no longer be sufficient - rather, Lord suggests, your reasons against intending to go to graduate school will be decisive. Thus, you are rationally required not to intend to go to graduate school. ${ }^{4}$

Importantly, it doesn't follow that your reasons to intend to go to law school are now decisive. This is important because, as Lord emphasises, it seems rationally permissible to change your mind (at least prior to taking any significant steps towards going to law school). So your reasons against intending to go to law school must be

\footnotetext{
${ }^{4}$ Of course, the case in which you first intend to go to law school and then form the intention to go to graduate school is only one way in which you might come to have inconsistent intentions - you might also form both intentions simultaneously. Lord suggests that in this case, each intention attenuates the other, so that both become rationally impermissible (31-2). I will put this version of the case aside.
} 
weighty enough to make it rationally permissible not to intend to go to law school. To explain this, Lord suggests that your reasons to intend to go to graduate school are also reasons against intending to go to law school. These reasons are not attenuated. Thus you possess sufficient reasons to intend to go to law school but also sufficient reasons not to intend to go to law school. And so it is rationally permissible both to maintain your intention to go to graduate school and also to drop it.

This story is ingenious, but I have my doubts. An initial worry is that the cases in which Intentions Attenuate applies look very different from other, more familiar, examples in which reasons to intend are attenuated. I think there are three main types of case.

First, there are cases in which it is natural to say that reasons to intend are attenuated because reasons to act are attenuated. To take some standard examples, the fact that the exhibition is on for several more months attenuates your reasons to see it today - and so your reasons to intend to see it today (cf. 31); the fact that someone is culpable for getting themselves into trouble might attenuate your reasons to help them - and so your reasons to intend to help them (Dancy 2004: 42).

Our cases are not like this. It's not particularly plausible that intending to go to law school makes the case for going to graduate school less strong. And in any case, I don't think Lord can say that the attenuation works in this way. That's because if intending to go to law school made your reasons to go to graduate school insufficient, then your reasons to go to law school would be decisive. And if your reasons to go to law school were decisive, then it would be a mistake to change your mind and drop your intention to go to law school. So Lord's view must be that intending an option attenuates the reasons for intending an alternative without attenuating the reasons for taking that alternative. 
Second, there are cases in which intending an option is not needed for taking that option. For example, you probably won't insult your students in class today, even if you don't intend not to insult your students in class today. It's plausible that this attenuates your reasons to intend not to insult your students, though not your reasons not to insult your students. But our cases are clearly not like this. Intending to go to law school doesn't make it that you will go to graduate school regardless of whether you intend to do so!

Third, there are cases in which intending an option will be ineffective. Suppose, for example, that you would be unlikely to stick with an intention to run a marathon - you would find the training too much of a hassle. We might think that this attenuates your reasons to intend to run the marathon (cf. Kolodny 2008: 369-71).

Our cases are in some ways like this. If you intend to go to law school, intending to graduate school does become less likely to be effective, given the conflict of intentions. However, if the ineffectiveness of intending to run a marathon attenuates your reasons to intend to run a marathon, it also surely attenuates your reasons to run the marathon. Otherwise, you might have decisive reasons to run the marathon but insufficient reasons to intend to run. That is not a plausible verdict. Again though, it's important for Lord's view that intending an option only attenuates the reasons to intend alternative options.

So Intentions Attenuate doesn't look like any of the more familiar examples of attenuators for reasons to intend. That is not in itself damning. Lord might have discovered a new category. To assess this, we need to consider his case for Intentions Attenuate. 
Lord's main argument is abductive: Intentions Attenuate explains 'a

particularly complicated data set' (33). ${ }^{5}$ By this, Lord means that it explains how we

can have cases, like the choice between law school and graduate school, in which (i)

prior to forming any intention, it is rationally permissible to intend to $\varphi$ and rationally

permissible to intend to $\psi$, (ii) once you form an intention to $\varphi$ or an intention to $\psi$,

forming the other intention is rationally impermissible, but (iii) it remains rationally

permissible to drop the intention you formed.

However, it is not clear that Lord's view does capture all the data. In

particular, it is not clear that Lord can maintain (iii). ${ }^{6}$ As noted, Lord holds that once

you intend, say, to go to law school, it remains rationally permissible to drop this

intention because you still possess sufficient reasons against intending to go to law

school. That is why your reasons to intend to go to law school are only sufficient, and

not decisive, even though you lack sufficient reason to intend to go to graduate

school.

What are these sufficient reasons against intending to go to law school?

According to Lord (32-3), they are provided by the same facts that are reasons to

intend to go to graduate school - for example, as these might be, your love of

\footnotetext{
${ }^{5}$ Lord also suggests that Intentions Attenuate is supported by the view that attenuators are reasons to place less weight on the reasons they attenuate (33). With Intention Attenuate, this view predicts that the fact that you intend to go to law school is a reason to place less weight, in deliberating, on the reasons to intend to go to graduate school. Lord finds this prediction intuitive. I find it hard to evaluate, because the cases Lord needs to appeal to are hard to keep in view. Ordinarily, you would deliberate about whether to intend to go to graduate school by deliberating about whether to go to graduate school (cf. Shah 2008). But as we've seen, Lord does not and should not claim that your intention to go to law school attenuates your reasons to go to graduate school. Furthermore, we ordinarily only deliberate in cases where we don't already take ourselves to have settled what to do. But if you intend to go to law school, then you will ordinarily take yourself to have settled what to do - you'll be going to law school. ${ }^{6}$ There may also be further data that Lord's account does not immediately explain. Here are two potential examples. First, before you form an intention about whether to go to law school or to graduate school, it is rationally impermissible to form both intentions. Second, once you intend to go to graduate school, it is rationally permissible to simultaneously drop this intention and form the intention to go to law school. Lord's view doesn't seem to immediately accommodate either of these claims. However, since these cases raise difficult issues about rationality and temporality, I leave them aside.
} 
philosophy, the independence promised by an academic career, and your aptitude for teaching.

While we can grant that these are reasons against intending to go to law school, it is clear that they are primarily reasons to intend to go to graduate school. They are only reasons against intending to go to law school because they are reasons to intend to go to graduate school, and going to graduate school is incompatible with going to law school. Thus these facts are only derivative reasons against intending to go to law school.

However, it is very plausible that derivative reasons are attenuated when the reasons from which they derive - their source reasons - are attenuated. The intuitive thought here is that insofar as the case for a reaction entirely derives from the case for another, weakening the case for the latter will weaken the case for former too. This thought is borne out by examples. You might have reasons to save now just because you have reasons to spend later. But if your reasons to spend later are attenuated, your reasons to save now are attenuated too. Or, you might have reasons to believe the conclusion just because you have reasons to believe the premises. Again, if your reasons to believe the premises are attenuated, your reasons to believe the conclusion are attenuated too.

This makes trouble for Lord. It implies that if your reasons to intend to go to graduate school are attenuated, and your reasons against intending to go to law school entirely derive from your reasons to intend to go to graduate school, then your reasons against intending to go to law school are attenuated too. And in that case, Lord cannot maintain that you are rationally permitted to drop the intention to go to law school because you possess sufficient reason against this intention. Intentions Attenuate thus fails to capture the data that Lord is interested in. 
If this is right, Lord's main case for Intentions Attenuate fails. Indeed, Intentions Attenuate generates mistaken predictions, and so should be rejected.

I conclude that we should be sceptical about Intentions Attenuate and thus be sceptical that Lord's account can explain the irrationality of intention inconsistency. This is a serious problem for his accounts of what rationality requires and permits.

\section{Ought}

I now turn to Lord's account of what we ought, full stop, to do - or, as Lord sometimes says, our 'full stop obligations'.

Lord holds that our full stop obligations are determined by the reasons we possess. Lord's view is thus a version of perspectivism. That is, he holds that what you ought to do depends on only some of the reasons there are - those that you possess, and so fall within your epistemic sphere, or 'perspective'. Perspectivism contrasts with objectivism, the view that what you ought to do is determined by all the reasons there are, independently of your perspective. ${ }^{7}$ An important part of Lord's case for perspectivism, and against objectivism, comes from the following argument (232):

(1) If the reasons in some set $\mathrm{S}$ make it the case that you ought to $\varphi$, then you can $\varphi$ because of the members of S.

(2) If you can $\varphi$ because of the members of S, then you possess the members of S.

(C) If the reasons in some set S make it the case that you ought to $\varphi$, then you possess the members of $\mathrm{S}$.

\footnotetext{
${ }^{7}$ This gloss on the distinction between objectivism and perspectivism assumes that obligations should be understood in terms of reasons. For a more general gloss, and further references, see Way and Whiting (2017).
} 
(2) states a prima facie plausible condition on being guided by reasons. If a fact is a reason for you to $\varphi$, but you do not possess that reason - for instance, because you are not in a position to know the fact - then plausibly you are not able to $\varphi$ in light of that fact. I shall grant this. ${ }^{8}$

What about (1)? This states a version of the appealing idea that our obligations must be action-guiding. Lord understands this idea in a specific way:

If you deny (1), then you are committed to thinking that... there are cases where the members of S make it the case that you ought to $\varphi$ and it's impossible for you to $\varphi$ and be creditworthy for $\varphi$-ing. I think this is deeply implausible.

It's implausible because it robs our full stop obligations of a certain kind of action guidingness. If we cannot perform the actions we are obligated to perform in a way that deserves credit, then those obligations are not action guiding. (234)

Lord's case for (1) thus rests on

(Credit) If the reasons in some set $\mathrm{S}$ make it the case that you ought to $\varphi$, then you can $\varphi$ in a way that is creditworthy.

In earlier work, Daniel Whiting and I presented a counter-example to Credit:

\footnotetext{
${ }^{8}$ Of course, 'can' may express a range of senses. In Way and Whiting (2017), we observe that 'can' in (2) should be taken to express specific ability - roughly, both a general ability and the opportunity to exercise that ability. (1) must therefore be taken in the same sense. I'll take this as read.
} 
DOCTOR A doctor is deciding whether to give drug A or drug B to a patient who has a painful and fatal disease. She knows that A will completely cure the patient, relieving all the patient's suffering and saving her life, and that B will not save the life of her patient but will relieve the patient's suffering. The doctor also knows that, if she tries to give one drug, she will be unable to give the other. However, though she is no position to know this, and despite evidence to the contrary, the doctor is unable... to give A. As it happens, the doctor gives B to the patient for the reason that it will relieve her suffering (Way and Whiting 2017: 367).

We claimed that the doctor ought to give drug B but cannot give drug B in a creditworthy way.

Lord agrees that the doctor ought to give drug B. He denies that she cannot give drug B in a creditworthy way. In fact, Lord thinks the doctor does give drug B in a creditworthy way. However, he grants that the doctor only deserves partial credit: 'while the act she performs expresses some good will in virtue of the fact that it shows concern for the patient's suffering, she also expresses a lack of good will in virtue of showing indifference towards the patient's life' (237).

I want to make two points about this response. First, as Lord acknowledges, it shows that Credit must be understood in a particular way. In particular, Lord must hold Partial Credit, not Full Credit:

(Full Credit) If the reasons in some set $\mathrm{S}$ make it the case that you ought to $\varphi$, then you can $\varphi$ for those reasons in a way that is fully creditworthy. 
(Partial Credit) If the reasons in some set S make it the case that you ought to $\varphi$, then you can $\varphi$ for those reasons in a way that is partially creditworthy (cf. 238).

This is problematic because, so it seems to me, Lord's arguments for Credit concern Full Credit, not Partial Credit. Lord supports Credit by appeal to putative cases in which you ought to $\varphi$ but, because you do not possess the reasons that determine this obligation, are not able to $\varphi$ in a creditworthy way. Consider Judith Thomson's case in which, due to an unforeseeable series of coincidences, flipping the light switch when you get home will electrocute your neighbour. As an objectivist, Thomson thought that you ought not flip the light switch. Lord objects:

there is simply no way you can do what you ought for the right reason... [T] only way you can do what you ought to do is by doing something idiotic. There's no way for the right-makers of your act to get any legitimate grip on you. But, we're supposed to believe, they require you to stumble around in the dark all the same. This is dubious (234).

However, similar concerns can be raised about the possibility of cases in which you ought to $\varphi$ but can only $\varphi$ in a way that deserves partial credit. When the doctor gives drug B, they are doing something grossly indifferent. And if it is dubious that we can be obliged to be idiotic, it is surely also dubious that we can be obliged to be grossly 
indifferent. Indeed, it is easy to change the example so that giving drug B is idiotic for instance, we can add that the Doctor's primary aim is to save the patient's life. ${ }^{9}$

Thus Lord's arguments for Credit do not support Partial Credit. If Lord agrees that Doctor undermines Full Credit, and thus wants to defend his perspectivism by appeal to Partial Credit, he needs to provide new arguments for Partial Credit.

The second point about Lord's response to Doctor is that it does not speak to some more general problems that the case raises for his views. As we've seen, Lord holds that what we ought to do and what we are rationally required to do are both determined by the reasons we possess. This means that Doctor bears on Lord's account of rational requirements, as well as his account of obligation. In fact, Doctor raises three problems for this account.

First, it is not plausible that the doctor is rationally required to give drug B. Again, this is perhaps clearest if we add that the doctor aims to save the patient's life. In that case, it is plainly irrational to give drug B. Given the doctor's evidence, it is clear that this will not achieve her (rational) aim.

Second, and relatedly, the case undermines a principle that plays an important role in Lord's arguments: 'whenever you are ex ante rational in $\varphi$-ing, you can be ex post rational in $\varphi$-ing' (101). Applied to Doctor, this implies that the doctor must be able to rationally give drug $\mathrm{B}$. But the doctor is not able to rationally give drug $\mathrm{B}$. Although she can give drug $\mathrm{B}$ for the reason that makes it rational to give drug $\mathrm{B}$, she is not able to give drug B in a way that is sensitive to the weight of this reason. Given

\footnotetext{
${ }^{9}$ What about Lord's claim that in Thomson's case the right-makers cannot get a 'legitimate grip' on you? I suggest that this is true in Doctor too. Although the doctor is aware of the facts which are rightmakers, she is not in a position to be sensitive to them as right-makers. Cf. 141.
} 
her evidence and aims, she is not able to give drug B in a way that would be sensible. ${ }^{10}$

Third, it is clear that it is rational for the doctor to believe that she ought to give drug A. She knows that drug A will completely cure the patient and relieve all her suffering, while drug B will only relieve the patient's suffering. And she has misleading but - we can stipulate - sufficient evidence that she can give drug A. If the doctor is nonetheless rationally required to give drug $\mathrm{B}$, this is a case in which it is rational for the doctor to be akratic. But akrasia is a paradigmatic form of irrational incoherence. (Indeed, Lord is keen to show that his view can explain why akrasia is irrational (45ff)).

I conclude that Lord's response to Doctor is unsuccessful. As things stand then, we should reject Credit. ${ }^{11}$ Since one of Lord's central arguments for perspectivism - and for his view that obligations are determined by possessed reasons - rests on Credit, this argument thus fails. We have also seen that Doctor raises problems for Lord's account of what rationality requires.

\section{Possession}

I now turn to Lord's account of possessed reasons:

\footnotetext{
${ }^{10}$ Lord could say that doctor is able to give drug B in a ex post partially rational way. This would raise issues parallel to those raised by the appeal to Partial Credit.

${ }^{11}$ Of course, other ways of defending Credit against Doctor are possible. In particular, it might be denied that the doctor ought to give drug B. For discussion, see Way and Whiting 2017: §7.2-7.3.
} 
(Possession) What it is for an agent A to possess $r$ as a reason to $\varphi$ provided by fact $f$ is for A to be in a position to manifest knowledge about how to use $r$ to $\varphi(124)$.

This is one of the book's most distinctive and interesting features. Many have assumed that possession is a purely epistemic (or doxastic) condition - that possessing reasons is simply a matter of, e.g. believing, or rationally believing, or knowing, the facts which provide reasons. Lord makes a powerful case that such conditions are insufficient. If Lois knows that the fish on her plate contains salmonella, but believes that salmonella is an entirely harmless bacteria, she may not possess the fact that her fish contains salmonella as a reason not to eat. Given her background belief, this fact does not bear negatively on the rational merits of eating the fish. But bearing on the rationality of our reactions is just what possessed reasons are supposed to do (97-99).

The central notion in Possession is that of knowing how to use a reason $r$ to $\varphi$. It does not seem to me that this is an ordinary notion, one that gets much expression in ordinary talk and thought. So we need some guidance on how it is to be understood.

What is it to 'use a reason'? A natural answer is that you use a reason $r$ to $\varphi$ just when $r$ is your reason for $\varphi$-ing. However, knowing how to use a reason $r$ to $\varphi$ is not simply a matter of being able to $\varphi$ in light of $r$. Knowing how to use a reason is 'a competence. It disposes one to get things right' (117).

This suggests that knowing how to use a reason is knowing how to use that reason in the right way. This raises an initial worry. It is not clear that there need be any such thing as the right way to use a reason. After all, reasons can be outweighed. 
And when they are, it doesn't seem like there is any right way to use them. Consider the good version of Lois' case, in which she does appropriately respond to the fact that her fish contains salmonella by refraining from eating the fish. Here it might nonetheless be true that the fish will be tasty, which is a reason to eat it. What is the right way for her to use this reason? It's not by eating the fish for that reason - that would be a terrible idea. Perhaps she should give some weight to this fact, or to some extent desire or be motivated to eat the fish by this fact? This seems dubious too. It might be fine for her not to give any thought to the fact that the fish is tasty. ${ }^{12}$

It thus remains unclear how we are to understand the notion of knowing how to use a reason. However, this may not matter for Lord's purposes. This is because Lord also elucidates the notion of knowing how to use a reason by appeal to certain dispositions (135ff). He thus has the option of directly analysing possession in terms of these dispositions, rather than going via know-how. ${ }^{13}$ For example, he could propose:

(Possession $_{\mathrm{D}}$ ) What it is for an agent $\mathrm{A}$ to possess $r$ as a reason to $\varphi$ is, in part, for $\mathrm{A}$ to be disposed to $\varphi$ when $r$ is a reason to $\varphi$ and be disposed to revise $\varphi$ ing when $r$ ceases to be a reason to $\varphi .^{14}$

\footnotetext{
${ }^{12}$ Nor should we say that the right way for her to use this fact is to not to give it any thought. Doing so would make possession too easy to come by. For example, it would imply that Lois possesses the reason provided by the fish containing salmonella in the original, bad version of the case, where it also seems appropriate for her not to give this any thought.

${ }^{13}$ This sometimes seems to be what Lord intends (e.g. p.111, n.26). But elsewhere he seems to take the dispositions to be posterior to the know-how (e.g. 139).

${ }^{14}$ This draws on the dispositions Lord describes in his account of what it is to $\varphi$ for a normative reason (138-9). Note that Possession could only state part of a a real definition of possession, since possessing a reason requires you to stand in some epistemic relation to it. Lord takes this to be implied by Possession, but it is not implied by Possession ${ }_{D}$.
} 
However, this account is also open to objection. Consider again a version of Lois' case in which Lois possesses the fact that the fish contains salmonella as a reason to refrain from eating the fish. Of course, Lois might also know that the fish will be tasty, which is a reason to eat it. According to Possession $\mathrm{D}$, Lois possesses this reason only if she is disposed to eat the fish when the fact that the fish will be tasty is a reason to eat it. But this disposition doesn't look like a good disposition to have. After all, it might lead her to eat the fish even though she knows it contains salmonella. It is surprising that possessing this reason requires her to have this liability of a disposition.

This worry might seem overstated. After all, if Lois possess the fact that the fish contains salmonella as a reason to refrain from eating the fish, she'll also be disposed to refrain from eating the fish. Her dispositions will clash and so at least one won't be manifested.

However, this clash of dispositions can only be expected to prevent her from eating the fish if her dispositions are sensitive to the weights of the respective reasons. What she needs are dispositions to refrain from eating the fish when the fact that it contains salmonella is a decisive reason to refrain, or to eat the fish only when the fact that it is tasty is (at least) a sufficient reason to eat the fish. These dispositions are indeed good dispositions to have. But they must be distinguished from the dispositions which, according to $\left(\right.$ Possession $_{\mathrm{D}}$ ) are partly constitutive of possessing reasons.

This suggests the following revision to Possession ${ }_{D}$ : 
(Possession $\left._{D^{*}}\right)$ What it is for an agent $\mathrm{A}$ to possess $r$ as a reason to $\varphi$ is, in part, for $\mathrm{A}$ to be disposed to $\varphi$ when $r$ is a sufficient reason to $\varphi$ and be disposed to revise $\varphi$-ing when $r$ ceases to be a sufficient reason to $\varphi$.

The problem with Possession ${ }_{D}^{*}$ is that reasons are not sufficient or insufficient simpliciter. They are only sufficient or insufficient relative to sets of reasons. The fact that the fish is tasty might be a sufficient reason to eat it, relative to the set of reasons which contains only the fact that the fish is tasty and, say, that it costs $\$ 10$. But it might be insufficient relative to a set of reasons which also contains the fact that the fish contains salmonella. Which set of reasons should we take Possession $\mathrm{D}^{*}$ to refer to? The only plausible answer seems to be: the set of reasons you possess. But then Possession $_{D^{*}}$ is circular. It defines what it is to possess a reason by reference to the reasons you possess. ${ }^{15}$

So while I am moved by Lord's case against purely epistemic accounts of possession, I am not yet convinced he has found the right way to move beyond them.

\section{Conclusion}

I have argued that possessed reasons may not be as important as Lord suggests.

Lord's view that what rationality requires and permits is that you react in ways that are appropriate given your possessed reasons faces a serious problem explaining the irrationality of inconsistent intentions. One of Lord's central arguments for his view that obligations are determined by possessed reasons rests on a claim, Credit, which is

\footnotetext{
15 The same worry would arise for a version of Possession $D$ which appealed to a disposition to be moved in proportion to the weights of reasons. This is because reasons plausibly only have weights relative to sets of reasons (cf. 141).
} 
subject to counter-examples. And Lord's account of possessed reasons itself also faces difficulties. For these reasons, I am yet to be fully convinced by some of the central claims of Lord's book. Nonetheless, I have learnt a great deal by working through it. ${ }^{16}$

\section{References}

Dancy, J. 2004. Ethics without Principles. Oxford: Oxford University Press.

Kiesewetter, B. 2017. The Normativity of Rationality. Oxford: Oxford University Press.

Lord, E. 2018. The Importance of Being Rational. Oxford: Oxford University Press. Kolodny, N. 2008. The Myth of Practical Consistency. European Journal of Philosophy 16 (3): 366-402.

Shah, N. 2008. How Action Governs Intention. Philosophers' Imprint 8: 1-19.

Way, J. 2018. Reasons and Rationality. In D. Star (ed), Oxford Handbook of Reasons and Normativity. Oxford: Oxford University Press, 485-503.

Way, J. and Whiting, D. 2017. Perspectivism and the Argument from Guidance.

Ethical Theory and Moral Practice 20 (2): 361-74.

${ }^{16}$ Thanks to Alex Gregory and Daniel Whiting for helpful comments and discussion. Special thanks to Errol Lord for illuminating discussions on these topics going back over ten years now. 